\title{
Dental Magnification Loupes: An Update of the Evidence
}

\author{
Mohammad A Aldosari
}

\begin{abstract}
Aim: To overview dental magnification loupes and to present the updated scientific evidence supporting its use.

Background: The practice of dentistry places considerable stress on the operators' visual acuity and musculoskeletal system. The use of magnification loupes has spanned many decades with claims of supporting visual and postural capacities of dental professionals and enhancing diagnostic and procedural accuracy.

Review results: Galilean and prismatic loupes both provide lightweight and clinically appropriate magnifications between $2.5 \times$ and $5.0 \times$, with beneficial features such as a fixed working distance and downward lens inclinations. Studies have found significantly increased detection and diagnostic abilities due to enhanced visibility and improved treatment outcomes for some investigated procedures. Postural studies have found improved positioning of the upper body when using loupes as compared to the positioning when using the naked eye, with practitioners experiencing reductions in musculoskeletal symptoms when using magnification loupes.

Conclusion:The current evidence supports the presence of some visual advantages of loupe magnification in diagnosis and treatment delivery. However, more clinical trials are needed to investigate different procedure outcomes over the long term. Further, there is robust scientific evidence advocating the use of loupe magnification for postural and musculoskeletal support.

Clinical significance: Dentistry is a visually and physically demanding profession with a high prevalence of musculoskeletal disorders among dental professionals. The use of loupe magnification potentially benefits both the dental healthcare provider and patients. Therefore, there is reason to consider the use of loupe magnification as an integral part of dental education and training, as well as a tool in the dental clinician's armamentarium.
\end{abstract}

Keywords: Dental loupes, Dental professionals, Literature review, Loupe magnification, Musculoskeletal disorders.

The Journal of Contemporary Dental Practice (2021): 10.5005/jp-journals-10024-3057

\section{BACKGROUND}

The use of magnification to enhance visualization in surgical procedures dates back as early as the 1860s, when operating microscopes were first used. ${ }^{1,2}$ This was followed by the development of binocular loupes, with the German surgeon Saemisch being credited with the first use of loupes in ophthalmic surgery in $1876 .{ }^{5}$ The magnification loupes were first used in dentistry during the first half of the 20th century. ${ }^{6}$ In 1978, Apotheker and Jako developed the first surgical microscope for use in dental practice. ${ }^{7}$ Although dentistry has been primarily performed with unaided eyes, the use of magnification loupes as a visual aid by dentists has spanned many decades with continuous incremental improvements in the design and efficacy. ${ }^{5,6}$ A survey among dentists, performed in 2019, has described magnification loupes as one of the significant technological developments in this profession. ${ }^{8}$

Dentistry is a visually demanding profession, requiring interaction with small-sized biological and nonbiological structures on a daily basis. Therefore, improving visual access is a desirable benefit. To improve visibility, dental practitioners typically attempt to move their heads closer to their operating fields. However, this leads to unfavorable postural changes, such as an inclined back, twisted neck, and potentially compromising positions. These unergonomic practices are considered one of the main reasons for the high prevalence of musculoskeletal disorders among dentists. ${ }^{9-11}$ The nature of dental work requires the involvement of several parts of the upper body, including the head, neck, shoulders, and arms, as well as the back. In a systematic review and meta-analysis by Lietz et al., the annualized prevalence of musculoskeletal disorders was as high as $78 \%$ in dentists, with the neck and upper back being the most common areas of pain. ${ }^{12,13}$
College of Dentistry, King Saud University, Riyadh, Kingdom of Saudi Arabia

Corresponding Author: Mohammad A Aldosari, College of Dentistry, King Saud University, Riyadh, Kingdom of Saudi Arabia, e-mail: MAIDosari@ksu.edu.sa

How to cite this article: Aldosari MA. Magnification Loupes: An Update of the Evidence. J Contemp Dent Pract 2021;22(3):310-315.

Source of support: Nil

Conflict of interest: None

In addition, dental hygienists and dental assistants have a high prevalence of musculoskeletal disorders, with faulty and awkward postures being one of the main risk factors. ${ }^{14-16}$ To mitigate these musculoskeletal dysfunctions in the dental profession, methods like using ergonomic seats, ergonomic training, and use of magnification loupes have been proposed..$^{12}$

However, even with ideal working postures, the visual discrimination of small structures from a distance is a challenging task. In theory, increasing the apparent size of objects within these working fields should provide the operator with an advantage in diagnosis, treatment, or both. This aspect becomes more valuable with any deterioration of eyesight. Many studies on eye-charts and the effects of different working distances revealed a decline in the near-distance acuity with age increase. ${ }^{17-19}$ In addition, another type of visual impairment is presbyopia, a natural part of aging that is characterized by a progressive loss of lens accommodation due to sclerosis of the eye lens and decreased sensitivity to contrast that also comes with aging. 17,19 
One approach that incorporates the promise of improving both visual acuity and operator posture is the use of magnifying loupes. While the visual acuity improvement claims stem from the optical magnification, the postural and musculoskeletal benefits are asserted through features of the loupes such as the fixed working length and inclination angles of the lenses. ${ }^{20}$ Nevertheless, the use of magnification loupes has achieved neither widespread use nor acceptance. Some dentists and even dental educators avoid the use of magnification loupes either because they do not see the need of using them, or they lack the ability or experience of working with loupes. ${ }^{21}$ This review will provide a primer on the topic of magnification loupes in dentistry with an update of the evidence supporting its use by dental professionals. Compared to magnification loupes, modern surgical microscopes provide much higher magnification powers; however, they also have much more complex setups and are not as portable. This renders operating microscopes applicable only to certain procedures and settings, with approximately only $1 \%$ of dentists using surgical microscopes in practice. ${ }^{22}$ Therefore, this review shall provide an overview of the application of magnification loupes for diagnosis and treatment across dental specialties.

\section{Loupe Types and Magnification}

Magnification loupes are classified based on their design and construction technique of the lens systems into Galilean loupes and Keplerian (prismatic) loupes. The Galilean loupes typically utilize two lenses: an objective convex lens and a concave eyepiece lens. They provide magnifications on the lower end between $2.0 \times$ and $3.5 \times$, which is why Galilean loupes are suitable as generalpurpose dental loupes or starter magnification loupes for new users. Keplerian loupes utilize two or more convex lenses, with a prism between the lenses. Keplerian loupes have a wider range of magnification power but are usually designed to be between $3.5 \times$ and $4.5 \times$ for most dental uses, although higher magnifications are available. The prisms extend the light path, which in turn increases the magnification depth and provides a longer working distance. Compared to Keplerian loupes, Galilean loupes are smaller in size and lighter in weight but provide a smaller field of view and shorter working distance. They are also less expensive due to their simpler design.
Regardless for the lens system used, the most common loupe magnification power used for general dental work is between $2.0 \times$ and 3.5 $\times$. Magnifications of $4.0 \times$ and higher are considered high power, and some experienced operators prefer these high-powered magnifications for endodontic surgeries and periodontal microsurgeries and other uses requiring very highdetail discrimination. ${ }^{23}$ However, this increased magnification power results in a smaller field of view and limited depth of field and is recommended for more experienced users. Other than the magnification, there are other loupe features to be aware of when choosing a magnification loupe for dental use. Having a large field of view allows one to see more structures within the line of vision. The steeper the inclination angle, the more upright is the head and neck position, and a customizable fixed working distance allows for an erect lower and upper back. A good quality loupe set should be custom made by the loupe manufacturer to fit the user and better address the operator's size and line of vision (Fig. 1).

In a series of studies by Eichenberger et al. and Perrin et al. comparing Galilean and Keplerian lens systems, the latter prismatic loupes were found to provide higher visual acuity and allow better detection of details for dentists over 40 years of age due to the higher magnification of the Keplerian loupes. ${ }^{17,24-26}$ However, the difference between the two loupe systems is generally not clinically significant, and both improve the visual acuity when compared to the naked eye and provided similar improvements in body posture and neck flexion. ${ }^{27-29}$

\section{Loupe Magnification for Visual Detection and Diagnosis}

One of the primary reasons for clinicians to seek the aid of magnification loupes is the improvement of diagnosis by an increase in the operator's visual acuity. In a study that used miniature Snellen charts placed inside prepared artificial teeth, Wajngarten et al. reported higher visual acuity scores when the operators used $3.5 \times$ or $4.0 \times$ magnifying loupes as compared to those with unaided eyes. ${ }^{28}$ This improvement in visual acuity was also found when using $2.5 \times$ magnification in a different study by Urlic et al. ${ }^{30}$ A study by Goel et al. found that the use of magnifying loupes combined with air drying helped in more reliable detection

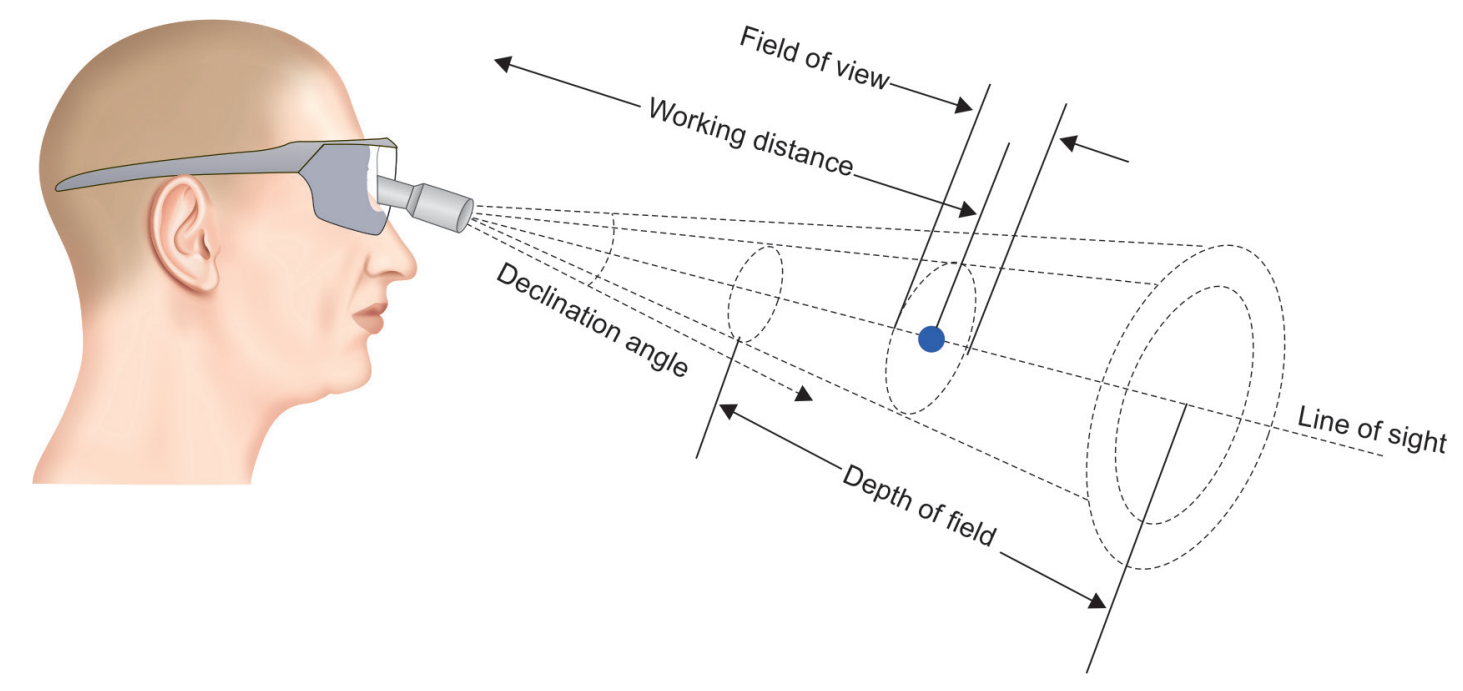

Fig. 1: Magnification loupe features (Adapted from James T and Gilmore, 2010) 
of early carious occlusal lesions more reliably when compared with the unaided eye. ${ }^{31}$ A study by Gupta et al. reported that in a sample of 300 children, loupe magnification with air-drying was more effective than unaided vision and as effective as using the DIAGNOdent device for detection of incipient caries. ${ }^{32}$

In an endodontic study comparing cone-beam computed tomography, magnification loupes, and naked vision, Vasundhara et al. found a higher ability to locate the second mesiobuccal canal using $3.5 x$ magnification loupes than with the naked eye. ${ }^{33}$ In addition, an in vitro study by Perrin et al. compared the different magnification methods and the naked eye for the ability of endodontists to visualize a $0.05 \mathrm{~mm}$ structure at multiple locations on a molar. They found that the surgical microscope provided the best visual acuity; however, loupes still provided superior visibility for the operators for all locations on the molar when compared to unaided eyes..$^{25}$ In periodontal procedures, magnification aids in the detection of residual calculus; ${ }^{23,34}$ most available studies on periodontal tissues have investigated the effects of the higherpowered surgical microscopes with favorable results. ${ }^{35}$

In terms of visual capacity and aging, there is a well-established pattern of decrease in visual acuity in both the general population and dentists, and the use of magnification loupes as a visual aid is encouraged with increased dental practice years as a means of compensating for any normal decline in visual acuity due to aging and presbyopia. 26,36

\section{Loupe Magnification for Procedures and Outcomes}

Magnification loupes were also studied for their potential to improve procedural outcomes. Maggio et al. evaluated the effect of loupe magnification on the performance of a sample of dental students in a simulation lab. They found improvements in the number of teeth preparations performed, the time needed for each preparation, and the need for assistance for each exercise when loupe magnification was used. ${ }^{37}$ The increase in the performance among dental students was also observed in a study by Narula et al. where magnification loupes were utilized for the first time to prepare for class II preparation. ${ }^{38}$ Braga et al. found that loupe magnification increased the quality of endodontic access preparations and prosthodontic crown preparations in a sample of dental students. ${ }^{39}$ In a sample of general dentists, Eichenberger et al. demonstrated a significant increase in the precision of tooth preparation in the simulation lab when using $2.5 \times$ loupe magnification compared to tooth preparation with the unaided eye. ${ }^{40}$ In laboratory-based veneer preparation, Pecheva and his group concluded that either $2.5 \times$ or $6.0 \times$ magnification gives better preparation depth and higher accuracy of cut dentinal tissues compared to the unaided eye. ${ }^{41}$ In a clinical trial, Wong et al. found that dentists with no prior use of magnification loupes experienced reduced treatment times for nonsurgical endodontic treatment. ${ }^{42} \mathrm{~A}$ randomized clinical trial by Taschieri et al. followed a sample of patients who underwent magnification-aided endodontic surgery for 1 year. They reported higher success rates for endodontic surgery with either loupes or surgical microscopes than with the unaided eye. ${ }^{43}$

In orthodontics, the utilization of magnification tools has been advocated for more precise attachment of orthodontic brackets, lingual appliances, and composite flash removal. ${ }^{44}$ In a randomized clinical trial by Baumann et al., they investigated the effect of using $2.5 \times$ dental loupes during orthodontic adhesive removal during debonding. They found that compared to the unaided vision, using magnification decreased the amount of enamel damage, line angle grooves, and composite residues on all teeth. ${ }^{45}$
The effectiveness of scaling and root planning with magnification was also studied. Mohan et al. examined premolars that underwent scaling and root planning and then extracted them under an electronic microscope. The results showed a significant improvement in the amount of remaining supragingival and subgingival calculus, removal of diseased cementum, and smoothness of root surfaces in the teeth scaled under magnification, a result that was also supported by Dawal et al. ${ }^{46,47}$

In the treatment of intra-bony defects, there was a significant improvement in clinical and radiographical measures due to the use of magnification. ${ }^{48,49}$ In cases where the lingual flap is a crucial part of the procedure, as in bone augmentation procedures or during third molar extraction, damage to the lingual nerve is possible and, fortunately, can be prevented by microsurgery and high magnification. ${ }^{50} \mathrm{~A}$ systematic review by Moro et al. concluded that using magnification loupes as an adjunct to microsurgical instruments in mucogingival surgery maximized the success of the procedures by providing better root coverage percentage, improved esthetics, and reduced postoperative pain and discomfort. ${ }^{51}$ Kato et al. compared the use of magnification loupes and surgical microscopes in cleft lip and palate repair, and found no difference in the duration of the procedure, ease of use, or complications between the two magnification methods, and stated that both could be used successfully in these operations. ${ }^{52}$

The use of magnification has been advocated during tooth preparation for the fabrication, impression, and cementation of dental crowns and fixed prosthetics. The use of magnification in the dental laboratory by dental technicians has also been encouraged to increase the accuracy of the fixed prosthesis from the impression stage to the final product. ${ }^{53,54}$ However, not all studies have found positive effects of using magnification loupes on treatment outcomes. Corbella et al. examined the effects of supragingival scaling using either $2.5 \times$ magnification or the naked eye. They found no differences in the treatment outcomes and also found that using loupes resulted in longer procedure times. ${ }^{55} \mathrm{~A}$ review of studies conducted in 2010 found no differences in treatment outcomes when prospectively comparing endodontic surgeries performed using magnification and the naked eye. ${ }^{56}$ This finding might be related to the superior properties of surgical microscopy in endodontic surgeries as compared to magnification loupes. ${ }^{57}$

\section{Musculoskeletal and Postural Effects}

One of the most prevalent occupational hazards of the dental profession is the development of musculoskeletal disorders. ${ }^{13}$ The studies examining the prevalence of neck and back musculoskeletal symptoms among dental professionals have found it to range between 17 and 83\%, depending on the study. ${ }^{13,58}$ The assumed musculoskeletal benefits of loupes stem from the fixed working distance of the magnification loupes and the declination angles. ${ }^{59}$ These two parameters force the operator to maintain a more erect spine and a more neutral neck position during examination and treatment. $^{27,59}$

A systematic literature review, published in 2020, concluded that the use of magnification loupes is the most effective type of equipment modification to reduce musculoskeletal symptoms. ${ }^{12}$ Using motion capture technology, it was found that using any type of loupe magnification reduces forward flexion of the neck when performing periodontal probing. ${ }^{27}$ This observation was similar to that in a study by Carpentier et al., which found significant spontaneous improvements in the positions of the head, trunk, and neck, but not in the arms, among students who used loupes 
as compared to those working with unaided eyes. ${ }^{59} \mathrm{~A}$ systematic review by Plessas and Delgado in 2018 examined the effects of ergonomic seats and magnification loupes in the prevention of musculoskeletal disorders. They found that using magnification loupes relieved shoulder and arm pain but not neck pain. ${ }^{60}$ Further, muscle activity of the neck and shoulders was assessed using surface electromyography in 36 dentists, and the results showed reduced activity when using magnification loupes; the reduction was more pronounced on combining the use of magnification and an ergonomic stool. ${ }^{61}$

To investigate the effects of the declination angle of the loupes, a pilot study on a group of hygienists using magnification loupes with manufacturer-determined declination angle and customized declination angle loupes was performed. Trunk flexion was reported to be less in the latter group, whereas neck flexion was not different between the two loupes types, but was significant compared to the use of no loupes. ${ }^{62}$

Many studies have reported pain reduction values among dentists in different body areas, when using magnification loupes.9,60,63-65 Improvements in posture while wearing loupes have also been perceived by hygienists. ${ }^{15,62} \mathrm{~A}$ systematic review assessing interventions that improve musculoskeletal symptoms concluded that using equipment, such as magnification loupes, along with indirect vision, has a high impact on reducing upper and lower body problems. ${ }^{58}$

\section{Challenges, Limitations, and Future Developments}

Dental practitioners' physical and psychological well-being is an important factor for quality care delivery and a prolonged career. Therefore, it is expected that healthcare systems and insurers over time will embrace and promote the technology that will help improve healthcare provider's own fitness, health, and wellbeing, in addition to improving the outcomes of rendered treatments. The addition of magnification loupes to the armamentarium of a dental healthcare worker could be a cost-effective approach to achieving these goals.

At the dental school level, studies have shown approximately 12.3 to $68 \%$ of dental students use magnification, which largely depends on the location of the dental school. ${ }^{3,66}$ Also, dental students have a positive impression and good acceptance of magnification loupes when trying them during simulation or clinical training. ${ }^{66,67}$ Therefore, introducing the loupes early in their dental education can teach them the importance of ergonomics when providing oral care. This also has the potential to reduce overall musculoskeletal issues over their careers and reduce the associated financial and psychological burdens of the future professionals in this field. Consequently, it is advisable to include visual magnification training as an integral part of dental school curricula. In the future, magnification loupes can even be used as educational tools by teachers or trainers for live demonstrations to students and instructions, as the loupes can be connected to screens and projectors.

Dental loupes have a few disadvantages that are important to note. One major hindrance to the widespread use of magnification loupes in dentistry is its accessibility. There are added financial costs to acquire and maintain high-quality loupes over the years, and it is certainly a larger burden in the early years of dental training and practice. More widespread use over time might lower costs through economies of scale. Accessibility is also compounded by the absence of reputable vendors and service centers of quality loupes in some developing countries. ${ }^{66} \mathrm{It}$ should be noted that care must be taken as magnification loupes are nondisposable, and they should be disinfected appropriately. A study on 25 magnification loupes revealed contamination after 5 days of use, where $40 \%$ of the loupes were described as moderately to highly contaminated with aerobic and anaerobic colony-forming units. ${ }^{68}$ Consistent disinfection and prophylaxis of the loupes are crucial, as in any other dental device, to avoid cross-contamination. ${ }^{4}$

There is still a shortage of randomized clinical trials to compare outcomes between treatments done with and without magnification in most specialties and procedures. It was also noted that most observational studies on the effects of musculoskeletal disorders have short follow-up periods. Studies of longer duration are necessary for evidence of any sustained benefits of magnification on the treatment outcomes in patients and prevention of physical disorders of operators.

\section{Conclusion}

The use of magnification loupes in dentistry has the potential to enhance the operator's visual acuity, enabling better diagnosis and treatment. Although, more studies are needed to elucidate the effects of loupe magnification on long-term procedure outcomes. In relation to the musculoskeletal and postural effects of using dental loupes, substantial evidence supports the use of the loupes to improve operator positioning and reduce physical disorders. Nevertheless, the application of this technology is still not widespread or accepted as a standard of care, and more efforts are necessary to promote the adoption of magnification loupes early in the dental professionals' careers.

\section{Clinical Significance}

The dental profession must prepare for a future with greater emphasis on the efficiency of healthcare, while maintaining the health and comfort of the dental clinician. Regular use of magnification loupes in dental practice is a promising approach that could help the clinician in overcoming both challenges effectively.

\section{References}

1. Wynne L. The selection and use of loupes in dentistry. Dent Nurs 2014;10(7):390-392. DOI: 10.12968/denn.2014.10.7.390.

2. Kriss TC, Kriss VM. History of the operating microscope: from magnifying glass to microneurosurgery. Neurosurgery 1998;42(4):899-907. DOI: 10.1097/00006123-199804000-00116.

3. Aboalshamat K, Daoud O, Mahmoud LA, et al. Practices and attitudes of dental loupes and their relationship to musculoskeletal disorders among dental practitioners. Int J Dent 2020:8828709. DOI: 10.1155/2020/8828709.

4. Low JF, Dom TNM, Baharin SA. Magnification in endodontics: a review of its application and acceptance among dental practitioners. Eur J Dent 2018;12(4):610-616. DOI: 10.4103/ejd.ejd_248_18.

5. Shanelec DA. Optical principles of loupes. J Calif Dent Assoc 1992;20(11):25-32. PMID: 1284393

6. Kroll A. The use of optical loupes in dentistry. Dent Items Interest 1947;69(3):267-269. PMID: 20294285

7. Apotheker $\mathrm{H}$, Jako GJ. A microscope for use in dentistry. J Microsurg 1981;3(1):7-10. DOI: 10.1002/micr.1920030104.

8. Heft MW, Fox CH, Duncan RP. Assessing the translation of research and innovation into dental Practice. JDR Clin Trans Res 2020;5(3):262-270. DOI: $10.1177 / 2380084419879391$.

9. Mulimani P, Hoe VC, Hayes MJ, et al. Ergonomic interventions for preventing musculoskeletal disorders in dental care practitioners. Cochrane Database System Rev 2018;10(10):CD011261. DOI: 10.1002/14651858.CD011261.pub2. 
10. Fals Martinez J, Gonzalez Martinez F, Orozco Paez J, et al. Musculoskeletal alterations associated factors physical and environmental in dental students. Braz J Epidemiol 2012;15(4):884895. DOI: 10.1590/s1415-790x2012000400018.

11. Kumar VK, Kumar SP, Baliga MR. Prevalence of work-related musculoskeletal complaints among dentists in India: a national cross-sectional survey. Indian J Dent Res 2013;24(4):428-438. DOI: 10.4103/0970-9290.118387.

12. Lietz J, Ulusoy N, Nienhaus A. Prevention of musculoskeletal diseases and pain among dental professionals through ergonomic interventions: a systematic literature review. Int J Environ Res Public Health 2020;17(10):3482. DOI: 10.3390/ijerph17103482.

13. Lietz J, Kozak A, Nienhaus A. Prevalence and occupational risk factors of musculoskeletal diseases and pain among dental professionals in Western countries: a systematic literature review and meta-analysis. PLoS One 2018;13(12):e0208628. DOI: 10.1371/ journal.pone.0208628.

14. Hayes MJ, Smith DR, Cockrell D. An international review of musculoskeletal disorders in the dental hygiene profession. Int Dent J 2010;60(5):343-352. https://doi.org/10.1922/IDJ_2514Hayes10

15. Hayes MJ, Smith DR, Taylor JA. Musculoskeletal disorders and symptom severity among Australian dental hygienists. BMC Res Notes 2013;6:250. DOI: 10.1186/1756-0500-6-250.

16. Morse T, Bruneau H, Dussetschleger J. Musculoskeletal disorders of the neck and shoulder in the dental professions. Work 2010;35(4):419429. DOI: 10.3233/WOR-2010-0979.

17. Perrin $P$, Eichenberger $M$, Neuhaus KW, et al. Visual acuity and magnification devices in dentistry. Swiss Dent J 2016;126(3):222-235. PMID: 27023468

18. Perrin P, Neuhaus KW, Lussi A. The impact of loupes and microscopes on vision in endodontics. Int Endodont J 2014;47(5):425-429. DOI: 10.1111/iej.12165.

19. Burton JF, Bridgman GF. Presbyopia and the dentist: the effect of age on clinical vision. Int Dent J 1990;40(5):303-312. PMID: 2080952

20. Rucker LM, Beattie C, McGregor C, et al. Declination angle and its role in selecting surgical telescopes. J Am Dent Assoc 1999;130(7):10961100. DOI: 10.14219/jada.archive.1999.0343.

21. Meraner M, Nase JB. Magnification in dental practice and education: experience and attitudes of a Dental School Faculty. J Dent Educ 2008;72(6):698-706. https://doi.org/10.1002/j.00220337.2008.72.6.tb04535.x

22. van As GA. Magnification alternatives: seeing is believing, Part I. Dent Today 2013;32(6):82-87. PMID: 23802377

23. Mamoun JS. A rationale for the use of high-powered magnification or microscopes in general dentistry. Gen Dent 2009;57(1):18-26; quiz 27-18, 95-16. PMID: 19146139

24. Eichenberger M, Perrin P, Neuhaus KW, et al. Influence of loupes and age on the near visual acuity of practicing dentists. J Biomed Opt 2011;16(3):035003. DOI: 10.1117/1.3555190.

25. Perrin P, Neuhaus KW, Eichenberger M, et al. Influence of different loupe systems and their light source on the vision in endodontics. Swiss Dent J 2019;129(11):922-928. PMID: 31460731

26. Eichenberger M, Perrin P, Ramseyer ST, et al. Visual acuity and experience with magnification devices in Swiss dental practices. Oper Dent 2015;40(4):E142-E149. DOI: 10.2341/14-103-C.

27. Branson BG, Abnos RM, Simmer-Beck ML, et al. Using motion capture technology to measure the effects of magnification loupes on dental operator posture: a pilot study. Work 2018;59(1):131-139. DOI: 10.3233/ WOR-172681.

28. Wajngarten D, Garcia P. Effect of magnification devices on dental students' visual acuity. PLoS One 2019;14(3):e0212793. DOI: 10.1371/ journal.pone.0212793

29. Pazos JM, Wajngarten $D$, Dovigo LN, et al. Implementing magnification during pre-clinical training: effects on procedure quality and working posture. Eur J Dent Educ 2020;24(3):425-432. DOI:: 10.1111/eje.12517

30. Urlic I, VerzakZ, Vranic DN. Measuring the influence of Galilean loupe system on near visual acuity of dentists under simulated clinical conditions. Acta Stomatol Croat 2016;50(3):235-241. DOI: 10.15644/ asc $50 / 3 / 6$

31. Goel D, Sandhu M, Jhingan P, et al. Effectiveness of air drying and magnification methods for detecting initial caries on occlusal surfaces using three different diagnostic aids. J Clin Pediatr Dent 2016;40(3):221-226. DOI: 10.17796/1053-4628-40.3.221.

32. Gupta N, Sandhu M, Sachdev V, et al. Comparison of visual examination and magnification with DIAGNOdent for detection of smooth surface initial carious lesion-dry and wet conditions. Int J Clin Pediatr Dent 2019;12(1):37-41. DOI: 10.5005/ jp-journals-10005-1588.

33. Vasundhara V, Lashkari KP. An in vitro study to find the incidence of mesiobuccal 2 canal in permanent maxillary first molars using three different methods. J Conserv Dent 2017;20(3):190-193. DOI: 10.4103/0972-0707.218308.

34. Mamoun J. Use of high-magnification loupes or surgical operating microscope when performing prophylaxes, scaling or root planing procedures. N Y State Dent J 2013;79(5):48-52. PMID: 24245463

35. Deepa D, Mehta DS, Munjal V. Periodontal microsurgery: a must for perio-aesthetics. Indian J Oral Sci 2014;5(3):103-108. DOI: 10.4103/0976-6944.144505.

36. Eichenberger M, Perrin P, Sieber KR, et al. Near visual acuity of dental hygienists with and without magnification. Int J Dent Hyg 2018;16(3):357-361. DOI: 10.1111/idh.12341

37. Maggio MP, Villegas $H$, Blatz MB. The effect of magnification loupes on the performance of preclinical dental students. Quintessence Int 2011;42(1):45-55. PMID: 21206933

38. Narula K, Kundabala M, Shetty N, et al. Evaluation of tooth preparations for Class II cavities using magnification loupes among dental interns and final year BDS students in preclinical laboratory. J Conserv Dent 2015;18(4):284-287. DOI: 10.4103/09720707.159724

39. Braga T, Robb N, Love RM, et al. The impact of the use of magnifying dental loupes on the performance of undergraduate dental students undertaking simulated dental procedures. J Dent Educ 2020. DOI: 10.1002/jdd.12437.

40. Eichenberger $M$, Biner $N$, Amato $M$, et al. Effect of magnification on the precision of tooth preparation in dentistry. Oper Dent 2018;43(5):501-507. DOI: 10.2341/17-169-C.

41. Pecheva A, Tsanova S, Raycheva R. In vitro evaluation of the impact of optical magnification on the preparation for veneers. J IMAB 2020;26(2):3155-3159. DOI: 10.5272/jimab.2020262.3155.

42. Wong AW, Zhu X, Zhang S, et al. Treatment time for non-surgical endodontic therapy with or without a magnifying loupe. BMC Oral Health 2015;15:40. DOI: 10.1186/s12903-015-0025-7.

43. Taschieri S, Del Fabbro M, Testori T, et al. Endodontic surgery using 2 different magnification devices: preliminary results of a randomized controlled study. J Oral Maxillofac Surg 2006;64(2):235-242. DOI: 10.1016/j.joms.2005.10.033.

44. Juggins KJ. The bigger the better: can magnification aid orthodontic clinical practice? J Orthod 2006;33(1):62-66. DOI: 10.1179/146531205225021420.

45. Baumann DF, Brauchli L, van Waes $H$. The influence of dental loupes on the quality of adhesive removal in orthodontic debonding.J Orofac Orthop 2011;72(2):125-132. DOI: 10.1007/s00056-011-0010-y.

46. Dadwal A, Kaur R, Jindal V, et al. Comparative evaluation of manual scaling and root planing with or without magnification loupes using scanning electron microscope: a pilot study. J Indian Soc Periodontol 2018;22(4):317-321. DOI: 10.4103/jisp.jisp_139_18.

47. Mohan R, Agrawal S, Gundappa M. Atomic force microscopy and scanning electron microscopy evaluation of efficacy of scaling and root planing using magnification: a randomized controlled clinical study. Contemp Clin Dent 2013;4(3):286-294. DOI: 10.4103/0976237X.118347.

48. Yadav VS, Salaria SK, Bhatia A, et al. Periodontal microsurgery: reaching new heights of precision. J Indian Soc Periodontol 2018;22(1):5-11. DOI: 10.4103/jisp.jisp_364_17. 
49. Cortellini P, Tonetti MS. Microsurgical approach to periodontal regeneration. Initial evaluation in a case cohort. J Periodontol 2001;72(4):559-569. DOI: 10.1902/jop.2001.72.4.559.

50. Karaca IR, Gündoğdu M. Magnification devices in dentistry: a review. Ortadogu Tıp Derg 2018;10(3):374-380. DOI: 10.21601/ ortadogutipdergisi.334951.

51. Moro M, Souto ML, Rovai E, et al. Effect of magnification on root coverage surgery. Braz J Oral Sci 2020;19. DOI: 10.20396/bjos. v19i0.8658221.

52. Kato $M$, Watanabe $A$, Watanabe $S$, et al. Cleft lip and palate reapair using a surgical microscope. Arch Plast Surg 2017;44(6):490-495. DOI: 10.5999/aps.2017.01060.

53. As GA. The use of extreme magnification in fixed prosthodontics. Dent Today 2003;22(6):93-99. PMID: 12847849

54. Winter RR, Cornell DF, Vingoren GJ, et al. Use of magnification in dental technology. J Esthet Restor Dent 2003;15(7):409-415. DOI: 10.1111/j.1708-8240.2003.tb00967.x.

55. Corbella S, Taschieri S, Cavalli N, et al. Comparative evaluation of the use of magnification loupes in supragingival scaling procedures. J Investig Clin Dent 2018;9(2):e12315. DOI: 10.1111/jicd.12315.

56. Del Fabbro $M$, Taschieri S. Endodontic therapy using magnification devices: a systematic review. J Dent 2010;38(4):269-275. DOI: 10.1016/j.jdent.2010.01.008.

57. Ma L, Fei B. Comprehensive review of surgical microscopes: technology development and medical applications. J Biomed Opt 2021;26(1):010901. DOI: 10.1117/1.JBO.26.1.010901.

58. Roll SC, Tung KD, Chang $\mathrm{H}$, et al. Prevention and rehabilitation of musculoskeletal disorders in oral health care professionals: a systematic review. J Am Dent Assoc 2019;150(6):489-502. DOI: 10.1016/j.adaj.2019.01.031.

59. Carpentier M, Aubeux D, Armengol V, et al. The effect of magnification loupes on spontaneous posture change of dental students during preclinical restorative training. J Dent Educ 2019;83(4):407-415. DOI: 10.21815/JDE.019.044.
60. Plessas A, Bernardes Delgado M. The role of ergonomic saddle seats and magnification loupes in the prevention of musculoskeletal disorders. A systematic review. Int J Dent Hyg 2018;16(4):430-440. DOI: 10.1111/idh.12327.

61. García-Vidal JA, López-Nicolás M, Sánchez-Sobrado AC, et al. The combination of different ergonomic supports during dental procedures reduces the muscle activity of the neck and shoulder. J Clin Med 2019;8(8):1230. DOI: 10.3390/jcm8081230.

62. Ludwig E, Tolle $S$, Jenkins $E$, et al. Magnification loupes influence on neck and trunk flexion of dental hygienists while scaling-a pilot study. Int J Dent Hygiene 2021;19(1):106-113. DOI: 10.1111/ idh.12470.

63. Lin S, Wu Z, Tang W, et al. Ergonomic risk exposure and work ability among young dental professionals in China: a cross-sectional study. J Occup Health 2020;62(1):e12154. DOI: 10.1002/13489585.12154

64. Lindegård A, Nordander $\mathrm{C}$, Jacobsson $\mathrm{H}$, et al. Opting to wear prismatic spectacles was associated with reduced neck pain in dental personnel: a longitudinal cohort study. BMC Musculoskelet Disord 2016;17:347. DOI: 10.1186/s12891-016-1145-1.

65. Pejčić $\mathrm{N}$, Petrović $\mathrm{V}$, Marković $\mathrm{D}$, et al. Assessment of risk factors and preventive measures and their relations to work-related musculoskeletal pain among dentists. Work 2017;57(4):573-593. DOI: 10.3233/WOR-172588.

66. Reinhardt JW, Romine JJ, Xu Z. Factors contributing to student satisfaction with dental loupes and headlights. Eur J Dent Educ 2020;24(2):266-271. DOI: 10.1111/eje.12493.

67. Bud M, Pricope R, Pop RC, et al. Comparative analysis of preclinical dental students' working postures using dental loupes and dental operating microscope. Eur J Dent Educ 2020. DOI: 10.1111/ eje.12627.

68. Zwicker DH, Price RB, Carr L, Li YH. Disinfection of dental loupes: a pilot study. J Am Dent Assoc 2019;150(8):689-694. DOI: 10.1016/ j.adaj.2019.03.008. 